\title{
DESAIN MODEL PEMBERDAYAAN DOSEN DI KOTA MEDAN
}

\author{
Fauzia Agustini, Dita Amanah, Dedy Ansari Harahap \\ Email: fauziaagustini24@yahoo.com; ditamnh@yahoo.com; \\ deanhar@yahoo.com
}

\begin{abstract}
ABSTRAK
Pengelolaan atau manajemen sumber daya manusia di perguruan tinggi khususnya untuk dosen, perlu diarahkan pada pemberdayaan dosen yang merupakan kegiatan bertujuan untuk memelihara dan meningkatkan kemampuan, kinerja dan produktivitas kerja dosen dalam peranannya sebagai tenaga akademik. Salah satu faktor yang dapat mendorong peningkatan produktivitas kerja adalah pemberdayaan sumber daya manusia, sebagai salah satu sumber daya organisasi. Dalam hal menjamin keberhasilan proses pembelajaran di perguruan tinggi, maka perlu adanya sebuah model pemberdayaan sumber daya manusia yang menggambarkan serangkaian proses yang dilakukan secara bertahap agar dapat mencapai hasil yang optimal sehingga akan berhasil meningkatkan produktivitas kerja dosen secara berkesinambungan.

Model ini hanya disesuaikan dengan kebutuhan dari perguruan tinggi maupun dosen yang bekerja pada perguruan tinggi tersebut. Penelitian ini telah mendesain model pemberdayaan dosen yang merupakan pengembangan dari model pemberdayaan sumber daya manusia yang selama ini berlaku untuk karyawan perusahaan. Penelitian ini mengkaitkan dengan kebutuhan dosen dan disesuaikan dengan tugas-tugas dosen di suatu perguruan tinggi khususnya kota Medan.
\end{abstract}

Kata Kunci : pemberdayaan dosen, perguruan tinggi, model, produktivitas

\begin{abstract}
Human resource management in universities especially for lecturers needs to be directed to lecturers empowerment which is an activity aimed to maintain and improve the ability, performance and productivity of lecturer's work in their role as academic staff. One of the factors that can encourage the improvement of work productivity is the empowerment of human resources, as one of the organizational resources.In terms of ensuring the success of the learning process in universities, it is necessary to have a model of human resource empowerment that describes a series of processes performed gradually in order to achieve optimal results so that it will succeed in improving the productivity of lecturer work on an ongoing basis.

This model is only tailored to the needs of the college and lecturers who work at the college. This research has designed the lecturer empowerment model which is the development of the human resource empowerment model that has been applied for company employees. This research relates to the needs of lecturers and adapted to the tasks of lecturers at a university, especially in Medan.
\end{abstract}

Keywords: empowerment of lecturer, college, model, productivity 


\section{PENDAHULUAN}

Secara umum pengertian pemberdayaan baru mulai memasyarakat di Indonesia yaitu pada tahun 1990-an, terutama dalam wacana manajemen. Kata pemberdayaan berasal dari kata bahasa inggris "empowerment" yang berasal dari kata dasar empower yang arti dasarnya memberikan kemampuan atau kapasitas melakukan sesuatu, sehingga dapat kita artikan pemberdayaan adalah proses memberikan kemampuan atau kapasitas untuk melakukan sesuatu. Di dalam manajemen umumnya selalu dikaitkan dengan sumber daya manusia, sehingga dikatakan pemberdayaan sumber daya manusia. Dilain pihak juga dapat digunakan kata pemberdayaan pada non-manusia misalnya lembaga-lembaga sosial.

Pada bidang pengajaran mutu seorang dosen erat kaitannya dengan tingkat produktivitas kerjanya yang antara lain berhubungan dengan kemampuan dosen tersebut dalam mempersiapkan pengajaran dan pada akhirnya akan dapat menghasilkan lulusan yang bermutu. Dalam rangka menyediakan lulusan yang bermutu, dosen harus mengetahui secara jelas apa yang menjadi kebutuhan pasar (market oriented) sehingga persiapan pengajaran yang dilakukan oleh dosen akan mengarah kepada kebutuhan tersebut (Agustini, 2015).

Goetsch \& Davis (1996) menyatakan pengertian pemberdayaan dengan pengertian partisipasi dengan istilah "Total Employee Involvemrnt and Empowerment" (TEIE) yang berarti pemberdayaan pada karyawan terjadi apabila mereka berpartisipasi aktif dalam proses pemikiran dan adanya kegiatan pada semua tingkatan organisasi.

Pemberdayaan tidak akan terjadi melalui perintah, petunjuk ataupun pengarahan saja, melainkan di dalam manajemen mutu terpadu partisipasi aktif yang sepenuhnya adalah kunci keberhasilan dalam usaha peningkatan mutu berkelanjutan. Kepelayanan bermutu akan terjadi dan dapat tumbuh serta membudaya dengan baik apabila SDM khususnya di perguruan tinggi diberdayakan secara berkelanjutan, dengan kata lain pemberdayaan semua anggota pengelola perguruan tinggi harus dilakukan secara bermutu dan berkelanjutan.diantaranya melakukan analisis jabatan perguruan tinggi, menyusun, menetapkan dan melaksanakan sistem pemberdayaan..

\section{KAJIAN PUSTAKA PEMBERDAYAAN DOSEN}

Yazdani, N.-M. Yaghoubi, \& E.S. Giri (2011) menyatakan pemberdayaan adalah sebuah konsep yang menghasilkan keuntungan bagi organisasi dan membuat karyawan merasa memiliki dan bangga terhadap organisasi.

Pemberdayaan karyawan mempunyai banyak manfaat bagi perusahaan diantaranya dapat unggul dalam persaingan seperti yang dikemukakan oleh Kahreh, S. M., Ahmadi, H., \& Hashemi (2011) yang menyatakan bahwa pemberdayaan karyawan sangat berhubungan secara positif dengan keunggulan bersaing. Pemberdayaan tidak hanya mempengaruhi sikap karyawan tetapi juga kinerja dan perilaku kerja karyawan (Chaijukul, 2010). Niehoff, Moorman, Blakely, \& Fuller (2001), menyatakan bahwa pemberdayaan mempunyai pengaruh positif pada loyalitas.

Kruja \& Oelfke (2009) telah melakukan penelitian pada Hotel Albanian menemukan bahwa pemberdayaan karyawan adalah sebuah komponen yang penting dari pelayanan organisasi terutama di industri perhotelan dan kadang-kadang ini adalah satu-satunya cara bagi organisasi untuk bertahan hidup, pada global ekonomi dimana tingginya tingkat persaingan.

Menurut Barizi (2010), pemberdayaan dosen ialah suatu kegiatan atau proses yang ditujukan untuk memelihara dan meningkatkan kemampuan, sikap, pengertian dan kinerja dosen dalam peranannya sebagai tenaga akademik pada masa kini dan masa yang akan datang.

Menurut Dee, Henkin, \& Duemer (2003), pemberdayaan pada bidang pendidikan mengacu pada guru yang menunjukkan tingkat komitmen yang tinggi pada pekerjaan mereka dan organisasi dan tingkat komitmen ini dapat dilihat dari kepercayaan diri mereka dan akibat dari kepercayaan diri mereka. Hasil penelitian menunjukkan bahwa pemberdayaan memberikan efek positif pada komitmen guru di sekolah. 
Pemberdayaan terhadap tenaga pengajar juga dapat meningkatkan kepuasan bagi para siswa, sehingga memotivasi pekerja membuat karyawan rela dan berkeinginan langsung dalam menyelesaikan tanggung jawabnya agar tujuan pekerja dan perusahaan bisa tercapai (Harahap, Agustini, Amanah, \& Riza, 2017). Sebuah penelitian yang dilakukan oleh Yunus, Ishak, \& Razak (2010) menunjukkan bahwa terdapat hubungan yang signifikan antara dimensi motivasi, pemberdayaan dan kualitas jasa dengan tingkat kepuasan siswa di Politeknik Malaysia.

\section{MODEL PEMBERDAYAAN SUMBER DAYA MANUSIA}

Model pemberdayaan sumber daya manusia dihasilkan oleh Khan (1997) merupakan sebuah model pemberdayaan yang dikembangkan dalam sebuah organisasi untuk menjamin keberhasilan proses pemberdayaan dalam organisasi seperti pada gambar berikut ini :
1. Desire
2. Trust
3. Confident
6. Communication
5. Accountability
4. Credibility

Sumber : Khan (1997)

\section{Gambar 1 \\ Model Pemberdayaan Syarafat Khan}

Adapun uraian dari masing-masing tahap pada model pemberdayan tersebut adalah sebagai berikut:

1. Desire

Tahap pertama dalam model empowerment adalah adanya keinginan dari manajemen untuk mendelegasikan dan melibatkan pekerjaan. Yang termasuk hal ini antara lain :

a. Pekerja diberi kesempatan untuk mengidentifikasikan permasalahan yang sedang berkembang.

b. Memperkecil directive personality dan memperluas keterlibatan pekerja

c. Mendorong terciptanya perspektif baru dan memikirkan strategi kerja.

d. Menggambarkan keahlian team dan melatih karyawan untuk mengawasi sendiri (self control)

2. Trust

Setelah adanya keinginan dari manajemen untuk melakukan pemberdayaan, langkah selanjutnya adalah membangun kepercayaan antara manajemen dan karyawan. Adanya saling percaya diantara anggota organisasi akan tercipta kondisi yang baik untuk pertukasan informasi dan saran adanya rasa takut. Hal-hal yang termasuk dalam trust antara lain :

a. Memberi kesempatan pada karyawan untuk berpartisipasi dalam pembuatan kebijakan.

b. Menyediakan waktu dan sumber daya yang mencukupi bagi karyawan dalam menyelesaikan kerja.

c. Menyediakan pelatihan yang mencukupi bagi kebutuhan kerja.

d. Menghargai perbedaan pandangan dan menghargai kesuksesan yang diraih oleh karyawan.

e. Menyediakan akses informasi yang cukup

\section{Confident}

Langkah selanjutnya setelah adanya saling percaya adalah menimbulkan rasa percaya diri karyawan dengan menghargai terhadap kemampuan yang dimiliki oleh karyawan. Hal yang termasuk tindakan yang dapat menimbulkan confident antara lain :

a. Mendelegasikan tugas yang penting kepada karyawan.

b. Menggali ide dan saran dari karyawan.

c. Memperluas tugas dan membangun jaringan antara departemen

d. Menyediakan jadwal job instruction dan mendorong penyelesaian yang baik. 
4. Credibility

Langkah keempat menjaga kredibilitas dengan penghargaan dan mengembangkan lingkungan kerja yang mendorong kompetisi yang sehat sehingga terciptanya organisasi yang memiliki performance yang tinggi. Hal yang termasuk credibility antara lain :

a. Memandang karyawan sebagai partner strategis.

b. Peningkatan target di semua bagian pekerjaan.

c. Memperkenalkan inisiatif individu untuk melakukan perubahan melalui partisipasi

d. Membantu menyelesaikan perbedaan-perbedaan dalam penentuan tujuan dan prioritas.

5. Accountability

Tahap dalam proses pemberdayaan selanjutnya adalah pertanggung jawaban karyawan pada wewenang yang diberikan. Dengan menetapkan secara konsisten dan jelas tentang peran, standard dan tujuan tentang penilaian terhadap kinerja karyawan, tahap ini sebagai sarana evaluasi terhadap kinerja karyawan dalam penyelesaian dan tanggung jawab terhadap wewenang yang diberikan. Hal ini yang termasuk accountability antara lain :

a. Menggunakan jalur training dalam mengevaluasi kinerja karyawan.

b. Memberikan tugas yang jelas dan ukuran yang jelas.

c. Melibatkan karyawan dalam penentuan standard dan ukuran.

d. Memberikan bantuan kepada karyawan dalam penyelesaian beban kerja.

e. Menyediakan periode dan waktu pemberian feedbeck

6. Communication

Langkah terakhir adalah adanya komunikasi yang terbuka untuk menciptakan saling memahami antara karyawan dan manajemen. Keterbukaan ini dapat diwujudkan dengan adanya kritik dan saran terhadap hasil dan prestasi yang dilakukan pekerja. Hal yang termasuk dalam communication antara lain :

a. Menetapkan kebijakan open door communication

b. Menyediakan waktu untuk mendapatkan informasi dan mendiskusikan permasalahan secara terbuka.

c. Menciptakan kesempatan untuk cross training.

Sedangkan model pemberdayaan yang kedua, dikemukakan oleh Bowen \& Lawler (1992). Pengetahuan, komunikasi, kepercayaan dan insentif diperkirakan mempunyai pengaruh terhadap pemberdayaan karyawan.

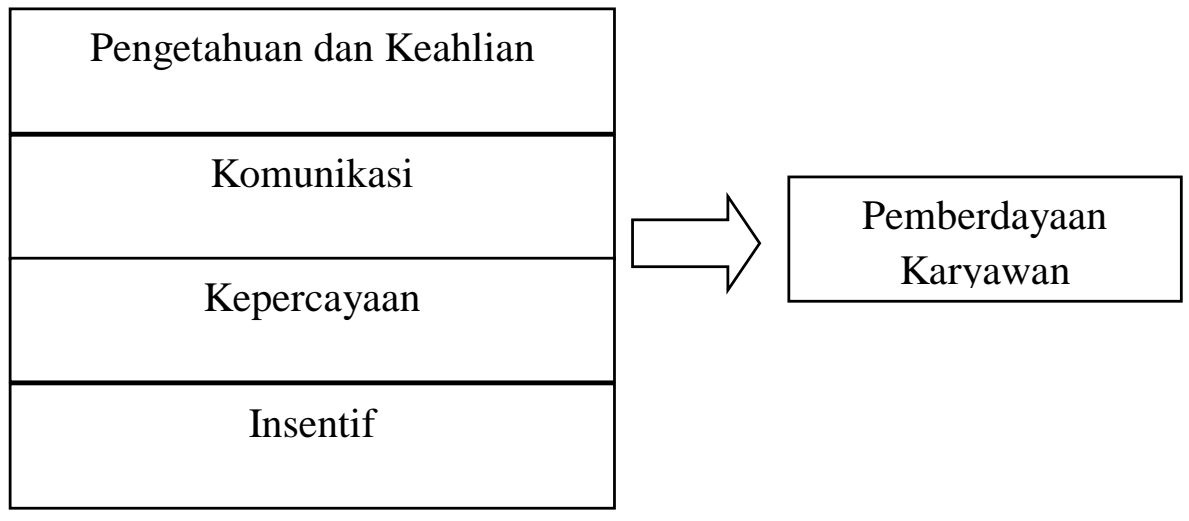

Sumber : Bowen \& Lawler (1992)

\section{Gambar 2}

Manajerial, Vol. 3 No.5 Juni 2018, Hal - 170

http://ejournal.upi.edu/index.php/manajerial/ 


\section{Model Pemberdayaan Bowen dan Lawler}

\section{METODE PENELITIAN}

Penelitian ini bersifat kualitatif. Terdapat dua jenis sumber data yang digunakan pada penelitian ini yaitu data primer dan data sekunder. Data primer bersumber dari hasil observasi sedangkan data sekunder diperoleh dari kajian literatur yaitu buku, internet dan jurnal.

Kegiatan observasi dilakukan melalui pengamatan terhadap kegiatan-kegiatan pemberdayaan dosen yang telah dilakukan, seperti workshop dan pelatihan.

\section{HASIL PENELITIAN DAN PEMBAHASAN}

Penelitian tentang pemberdayaan dosen tidak terlepas dengan usaha-usaha pemberdayaan dosen itu sendiri. Oleh karena itu, penelitian ini sudah melakukan usaha-usaha pemberdayaan tersebut yaitu melalui kegiatan workshop dan pelatihan. Observasi yang telah dilakukan oleh peneliti ini terkait dengan kedua kegiatan tersebut. Sehingga hasil observasi pada penelitian ini berhasil mendesain model pemberdayaan dosen.

Penelitian yang dilakukan untuk pemberdayaan dosen telah menghasilkan model pemberdayaan dosen seperti gambar berikut.

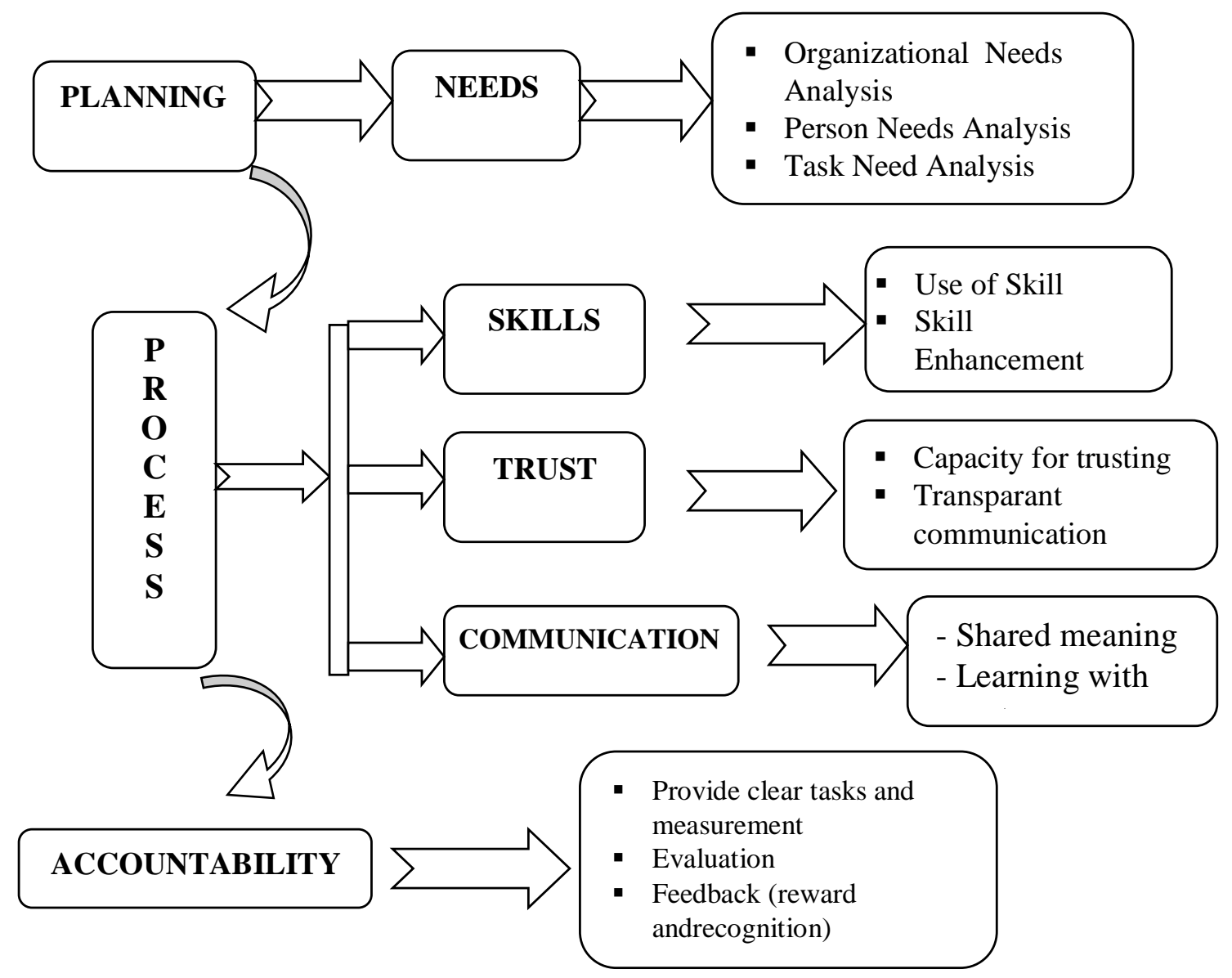

Gambar 3

Model Pemberdayaan Dosen 
Adapun uraian tahap-tahap tersebut adalah sebagai berikut :

1. Needs

Tahap pertama dalam model pemberdayaan adalah para dosen mempunyai kebutuhan yang sama. Pemberdayaan dosen diperlukan untuk memenuhi kebutuhan hidup. Kebutuhan hidup manusia terdiri atas beberapa tingkatan. Pemberdayaan dosen merupakan pemenuhan kebutuhan aktualisasi diri. Hal-hal yang termasuk dalam hal ini adalah :

a. Organizational need analysis

b. Person need analysis

c. Task need analysis

2. Skills

Keahlian adalah merupakan hal dasar yang diperlukan dalam melakukan pemberdayaan. Hal-hal yang termasuk dalam hal ini adalah :

a. Use of Skill

b. Skill enhancement

3. Trust

Setelah terdapat pengembangan pengetahuan maka perlu adanya membangun kepercayaan antara sesama dosen. Adanya saling percaya diantara para dosen akan tercipta kondisi yang baik untuk pertukaran informasi. Kepercayaan merupakan dasar bagi komunikasi yang efektif. Hal-hal yang termasuk dalam trust antara lain :

a. Capacity for trusting

b. Transparant communication

4. Communication

Langkah selanjutnya adalah adanya komunikasi yang terbuka untuk menciptakan saling memahami antara sesama dosen. Dalam melakukan kerjasama dengan para dosen sangat diperlukan komunikasi yang intens antara sesama dosen untuk pengembangan bahan ajar yang diperlukan bagi tiap mata kuliah. Hal-hal yang termasuk dalam communication antara lain :

a. Shared meaning

b. Learning with partners

5. Accountability

Tahap dalam proses pemberdayaan dosen selanjutnya adalah pertanggung jawaban para dosen pada tugas yang telah diberikan. Pada tahap ini, para dosen harus menyusun rancangan kegiatan belajar mengajar berbasis karakteristik kewirausahaan pada mata kuliah Pengantar Manajemen, Manajemen Pemasaran dan Manajemen Sumber Daya Manusia. Hal-hal yang termasuk dalam accountability antara lain :

a. Provide cleartasks and measurement

b. Evaluation

c. Reward

\section{KESIMPULAN DAN SARAN}

\section{Kesimpulan}

1. Pemberdayaan dosen merupakan kegiatan bertujuan untuk memelihara dan meningkatkan kemampuan, kinerja dan produktivitas kerja dosen dalam peranannya sebagai tenaga akademik.

2. Penelitian tentang pemberdayaan dosen tidak terlepas dengan usaha-usaha pemberdayaan dosen itu sendiri. Oleh karena itu, penelitian ini sudah melakukan usaha-usaha pemberdayaan tersebut seperti pelatihandan Workshop.

3. Model pemberdayaan dosen yang dihasilkan dari penelitian ini merupakan hasil dari kegiatan-kegiatan pelatihan dan workshop. Melalui kegiatan-kegiatan ini maka didapatlah Model Pemberdayaan Dosen. Adapun uraian tahap-tahap tersebut terdiri dari planning (needs analysis), process (skills, trust, communication), accountability (clear tasks and measurement, reward and recognition, evaluation). 


\section{Saran}

1. Pemberdayaan dosen merupakan hal yang sangat penting bagi peningkatan produktifitas kerja dosen. Oleh karena itu, pihak manajemen perguruan tinggi hendaknya lebih memperhatikan pemberdayaan dosen agar kualitas dosen meningkat dan mutu lulusan perguruan tinggi juga akan meningkat dan dapat diterima di lapangan pekerjaan.

2. Langkah-langkah dalam Model Pemberdayaan Dosen merupakan merupakan salah satu upaya untuk dapat meningkatkan produktivitas kerja dosen. Sebaiknya pihak manajemen dapat mengikuti langkah-langkah dalam model tersebut agar produktivitas kerja akan meningkat.

\section{Daftar Pustaka}

Agustini, F. (2015). Pemberdayaan Dosen Fakultas Ekonomi untuk Meningkatkan Produktivitas Kerja Melalui Kerjasama dengan Stakeholder di Kota Medan. Jurnal Pengabdian Kepada Masyarakat, 21(79), 24-38.

Barizi. (2010). Pemberdayaan dan Pengembangan Karir Dosen. Retrieved from https://dokumen.tips/documents/pemberdayaan-dosen-bz.html

Bowen, D. E., \& Lawler, E. E. (1992). The Empowerment of Service Workers: What, Why, How, and When. Sloan Management Review, 3, 31-39.

Chaijukul, Y. (2010). An examination of self-leadership performance mechanism model in thai private organization. The Journal of Behavioral Science, 5(1), 15-32.

Dee, J. R., Henkin, A. B., \& Duemer, L. (2003). Structural antecedents and psychological correlates of teacher empowerment. Journal of Educational Administration, 41(3), 257277. https://doi.org/10.1108/09578230310474412

Goetsch, D. L., \& Davis, S. B. (1996). Introduction to Total Quality: Quality Management for Production, Processing, and Services (2nd Editio). New York: Prentice Hall College Div. Retrieved from https://www.amazon.com/Introduction-Total-Quality-ManagementProduction/dp/0132325217

Harahap, D. A., Agustini, F., Amanah, D., \& Riza, S. (2017). The Comparison of Work Motivation between Employees and Staffs Based On Two Factor Theory of Motivation in PT PP London Sumatra Indonesia At Bah Lias Research Perdagangan North Sumatera Indonesia. International Journal of Engineering and Management Invention, 2(1), 187192.

Kahreh, S. M., Ahmadi, H., \& Hashemi, A. (2011). Achieving competitive advantage through empowering employees: An empirical study. Journal of Psychology, 3(2), 26-37.

Khan, S. (1997). The key to being a leader company: empowerment. Journal for Quality and Participation, (Januari/Februari).

Kruja, D., \& Oelfke, T. (2009). The Levels of Empowerment Impact on the Level of Employee Job Satisfaction: The Case of Albanian Hotels. TMC Academic Journal, 4(2), 91-106.

Niehoff, B. P., Moorman, R. H., Blakely, G., \& Fuller, J. (2001). The Influence of Empowerment and Job Enrichment on Employee Loyalty in a Downsizing Environment. Group \& Organization Management, $26(1), \quad$ 93-113. https://doi.org/10.1177/1059601101261006

Yazdani, B. O., N.-M. Yaghoubi, \& E.S. Giri. (2011). Factors Affecting the Empowerment of Employees (An Empirical Study). European Journal of Social Sciences, 20(2), 267-274.

Yunus, N., Ishak, S., \& Razak, A. (2010). Motivation, Empowerment, Service Quality and Polytechnic Students' Level of Satisfaction in Malaysia. International Journal of Busines and Social Science, 1(1), 120-128. Retrieved from http://www.ijbssnet.com/journals/10.pdf 